\title{
Patterns of Virus Exposure and Presumed Household Transmission among Persons with Coronavirus Disease, United States, January-April 2020
}

\author{
Rachel M. Burke, Laura Calderwood, Marie E. Killerby, Candace E. Ashworth, Abby L. Berns, \\ Skyler Brennan, Jonathan M. Bressler, Laurel Harduar Morano, Nathaniel M. Lewis, \\ Tiffanie M. Markus, Suzanne M. Newton, Jennifer S. Read, Tamara Rissman, Joanne Taylor, \\ Jacqueline E. Tate, Claire M. Midgley, for the COVID-19 Case Investigation Form Working Group
}

\begin{abstract}
We characterized common exposures reported by a convenience sample of 202 US patients with coronavirus disease during January-April 2020 and identified factors associated with presumed household transmission. The most commonly reported settings of known exposure were households and healthcare facilities; among case-patients who had known contact with a confirmed case-patient compared with those who did not, healthcare occupations were more common. Among case-patients without known contact, use of public transportation was more common. Within the household, presumed transmission was highest from older ( $\geq 65$ years) index case-patients and from children to parents, independent of index case-patient age. These findings may inform guidance for limiting transmission and emphasize the value of testing to identify community-acquired infections.
\end{abstract}

Author affiliations: Centers for Disease Control and Prevention, Atlanta, Georgia, USA (R.M. Burke, M.E. Killerby, L. Harduar Morano, N.M. Lewis, S.M. Newton, J. Taylor, J.E. Tate, C.M. Midgley) Cherokee Nation Assurance, Arlington, Virginia, USA (L. Calderwood), Virginia Department of Health, Richmond, Virginia, USA (C.E. Ashworth); Rhode Island Department of Health, Providence, Rhode Island, USA (A.L. Berns); Georgia Department of Health, Atlanta (S. Brennan); Alaska Department of Health and Social Services, Anchorage, Alaska, USA (J.M. Bressler); Pennsylvania Department of Health, Harrisburg, Pennsylvania, USA

(L. Harduar Morano); Vanderbilt University Medical Center, Nashville, Tennessee, USA (T.M. Markus); Vermont Department of Health, Burlington, Vermont, USA (J. Read); University of Vermont, Burlington (J.S. Read); Yale School of Public Health, New Haven, Connecticut, USA (T. Rissman)

DOI: https://doi.org/10.3201/eid2709.204577
Q oronavirus disease (COVID-19) was first identified in Wuhan, China, in December 2019 (1). The first reported case in the United States was identified in January 2020 (2); by mid-March, cases had been reported in all 50 states (3). On March 16, 2020, the White House Coronavirus Task Force published guidance for curbing community spread of COVID-19 (4); soon after, states began to enact stay-at-home orders (5). By late May 2020, all 50 states had begun easing restrictions; reported cases reached new peaks in the summer and then winter months of $2020(6,7)$. As restrictions further ease with increased availability of vaccine, and as pandemic fatigue may cause persons to adhere less consistently to recommended guidance such as masking and distancing, it may be informative to look back at exposures and within-household transmission during a period when few mitigation measures were in place. We characterized exposures common among persons with the earliest reported confirmed COVID-19 cases in the United States (onset mid-January through early April 2020) and identified factors associated with presumed household transmission.

This activity was reviewed by the Centers for Disease Control and Prevention (CDC) and was conducted consistent with applicable federal law and CDC policy. Forms were approved under the Office of Management and Budget (no. 0920-1011).

\section{Methods}

\section{Data Source}

The case investigation form (CIF; Appendix 1, https:/ / wwwnc.cdc.gov/EID/article/27/9/20-4577-App1. 
pdf) is a supplemental questionnaire designed by CDC in January 2020 to collect detailed demographic and epidemiologic information about a convenience sample of US COVID-19 case-patients reported by participating states. This purposive nonprobability sample was selected at the state level from persons identified through care-seeking, surveillance, or contact tracing as having COVID-19; infection with severe acute respiratory coronavirus 2 (SARS-CoV-2) was confirmed by reverse transcription PCR. CDC provided guidance for selection of case-patients across a range of ages and symptom severities (i.e., hospitalized and nonhospitalized), but states individually controlled sampling. The CIF was completed by state or local health department personnel or by CDC staff through case-patient or proxy interviews, along with medical record reviews (when relevant).

Case-patient demographic information included age, sex, race, ethnicity, and occupation. Workplace settings were classified according to 2012 census industry codes (Appendix 2, https:/ / wwwnc.cdc.gov/ EID/article/27/9/20-4577-App2.pdf). Clinical information included underlying conditions, symptoms, symptom onset date, dates of medical visits, and outcome (death or survival). For hospitalized casepatients, information was requested about whether the patient had been admitted to an intensive care unit, whether oxygen was received, admission and discharge dates, diagnosis, and location. Questions about exposure included whether in the 14 days before illness onset the case-patient had known exposure to a case-patient with laboratory-confirmed COVID-19 (COVID-19 contact) and, if so, the relationship and setting of the exposure. Case-patients were also asked about their exposure risks (activities and possible exposures in the 14 days before illness onset) including travel; friends, acquaintances, coworkers, or family members with fever or respiratory symptoms; close contact with (e.g., caring for, speaking with, or touching) any ill persons; attendance at a mass gathering (e.g., religious event, concert, sports event); public transportation use; attendance or work at a school or daycare; school or daycare attendance by household members; close contact with a contact of a laboratory-confirmed case-patient; close contact with someone with fever, acute respiratory illness, or both who had traveled internationally in the previous 14 days; and time in a healthcare setting as an employee, patient, or visitor.

The CIF also collected data on the case-patient's household members, defined as anyone who stayed overnight in the same residence as the case-patient during the 14 days before the case-patient's illness onset until the date of interview. Case-patients were asked for household members' age, sex, relationship to the case-patient, and whether each person had "experienced fever or respiratory symptoms (e.g., cough, sore throat, etc.) within 14 days before or after the COVID-19 patient's illness"; if yes, date of illness onset was collected. When the CIF was designed in January 2020, the most commonly reported COVID-19 signs and symptoms were fever and respiratory symptoms, and guidance for mitigation measures within households had not been widely distributed.

\section{Analysis of Exposures}

We compared exposures between those reporting known close contact with a COVID-19 case-patient in the 14 days before illness onset and those reporting no known contact. Categorical variables were compared by using $\chi^{2}$ or Fisher exact tests, as appropriate. Continuous variables were compared by using $t$ tests for normally distributed data and Wilcoxon rank sum tests otherwise. $\mathrm{p}<0.05$ was considered significant. Analyses were conducted in SAS version 9.4 (https:/ / www.sas. com) and R (https:/ / www.r-project.org).

\section{Analysis of Presumed Household Transmission}

We separately assessed presumed household transmission by using information about household members provided by the interviewed COVID-19 case-patient (CIF subject). In the absence of SARSCoV-2 testing data for all household members, we used reported signs and symptoms (i.e., fever or respiratory symptoms) as a proxy for symptomatic COVID-19 infection (i.e., household transmission). We analyzed households of $\geq 2$ members (including the CIF subject) if the CIF subject had experienced $\geq 1$ symptom (to enable identification of the first ill person [index case-patient] in the household), and symptom status was provided for $\geq 1$ other household member. We required that the earliest symptom onset date in the household be $\geq 1$ calendar day before symptom onset in subsequent case-patients (to limit effect of co-exposures outside the home) and that the earliest onset date in the household be $\geq 3$ days (our median serial interval) before the interview (to allow time for symptoms to develop in exposed household members). We considered presumed household transmission to have occurred if $\geq 1$ household member, in addition to the CIF subject, was reported as having fever or respiratory symptoms. The person with the earliest symptom onset date in a household was considered the index casepatient, regardless whether SARS-CoV-2 testing had been performed. Any members of a given household 
not identified as the index case-patient are hereafter referred to as household contacts.

We calculated the overall household attack rate for symptoms as the number of symptomatic household contacts divided by the total number of household contacts with reported symptom status, with Wilson score $95 \% \mathrm{CI}$, and the serial interval as the time from symptom onset in the index case-patient to first symptom onset in a household contact. We investigated age and sex of the index case-patients and their contacts, household size, and relationship of the contact to the index case-patient as possible correlates of contact symptom status by using generalized estimating equation logistic regression with households as the cluster and individual symptom status as the outcome; we used an exchangeable correlation matrix and robust SEs. We excluded household contacts missing symptom status from this analysis. We examined models for collinearity and reduced if necessary. We did not include hospitalization status of the index case-patient in models because of collinearity with index case-patient age. We dichotomized contact age ( $<18$ or $\geq 18$ years) to avoid collinearity with familial relationship and index case-patient age.

To explore the validity of using reported symptom status to estimate household symptomatic attack rates, we calculated sensitivity and specificity by using a subset of households for which complete reverse transcription PCR and serologic testing data were available (8). We conducted a sensitivity analysis by reclassifying data according to a range of plausible misclassification rates (Appendix 2).

\section{Results}

\section{Overview of the Analysis Population}

Data were collected from 16 states (Alaska, Arizona, California, Connecticut, Georgia, Hawaii, Illinois, Minnesota, Pennsylvania, Rhode Island, Tennessee, Utah, Virginia, Vermont, Washington, and Wisconsin) with 202 laboratory-confirmed COVID-19 casepatients with symptom onset during January 14April 4, 2020. Age of COVID-19 case-patients in the sample ranged from $<1$ to 95 years, almost all were symptomatic (195; 97\%), and 1 in 3 was hospitalized for management of COVID-19 symptoms (Appendix 2 Table 3). Of the 202 case-patients, 34 (17\%) reported having diabetes mellitus and 48 (24\%) reported hypertension.

\section{Exposures}

A total of $82(41 \%)$ case-patients reported known contact with a laboratory-confirmed COVID-19 case- patient in the 14 days before symptom onset. The most commonly reported exposure setting was the household (44/82; 54\%); within the household setting, the most frequently reported source of COVID-19 exposure was the spouse or partner of the COVID-19 case-patient $(16 / 44 ; 36 \%)$. The second most reported exposure setting was healthcare $(20 / 82 ; 24 \%) ; 14$ of the 20 persons exposed in the healthcare setting were healthcare workers, 4 were seeking care for unrelated medical issues, and 2 were visitors.

Among persons reporting no known COVID-19 contact, 20/84 (24\%) reported having close contact with an ill person. Persons with no known COVID-19 contact worked in a variety of industries, most commonly healthcare $(10 / 90 ; 11 \%)$; professional/office settings $(10 / 90 ; 11 \%)$; education $(9 / 90 ; 10 \%)$; and accommodation, food, or other services $(9 / 90 ; 10 \%)$ (Table 1). In comparison, 28\% (20/72) of persons with known COVID-19 contact reported working in healthcare. Persons with no known COVID-19 contact were significantly less likely than those with known contact to report spending time in a healthcare setting ( $p$ $=0.004$ ). However, they were somewhat more likely to report travel ( $38 \%$ vs. $26 \%)$ or attendance at a mass gathering (36\% vs. $21 \%)$ and significantly more likely to report use of public transportation (44\% vs. 16\%), compared with persons reporting known COVID-19 contact $(p=0.005)$

Of the 202 case-patients, $23(11.3 \%)$ reported no known contact with a confirmed case-patient, no travel within 14 days before illness onset, and none of the exposure risks assessed. These persons ranged in age from 21 to 88 years and were significantly older than those reporting $\geq 1$ possible exposure (median age 52 vs. 49 years; $p<0.0001$ ). They required hospitalization more frequently than those reporting $\geq 1$ possible exposure (52\% [12/23] vs. 30\% [54/179]; $p=$ 0.10 ), and were significantly more likely to report $\geq 1$ underlying medical condition $(87 \%$ [20/23] vs. $58 \%$ $[104 / 179] ; p=0.029)$. They were much more likely to report having diabetes mellitus $(43 \%[10 / 23]$ vs. $14 \%$ [24/176]; $\mathrm{p}=0.002)$.

\section{Analysis of Presumed Household Transmission}

A total of 69 case-patients provided data on the symptom status of $\geq 1$ household members and were included in our household analysis; in 48 (70\%) households, the CIF subject was the first or only symptomatic person in the household (i.e., was identified as the index case-patient; Figure 1). In half (34/69; 49\%) of included households, $\geq 1$ household member, in addition to the CIF subject, was symptomatic (i.e., virus transmission was presumed). Included households ranged in size 
Table 1. Reported exposures of 179 COVID-19 case-patients with submitted case investigation forms by known contact with a laboratory-confirmed COVID-19 case-patient, United States, January-April 2020*

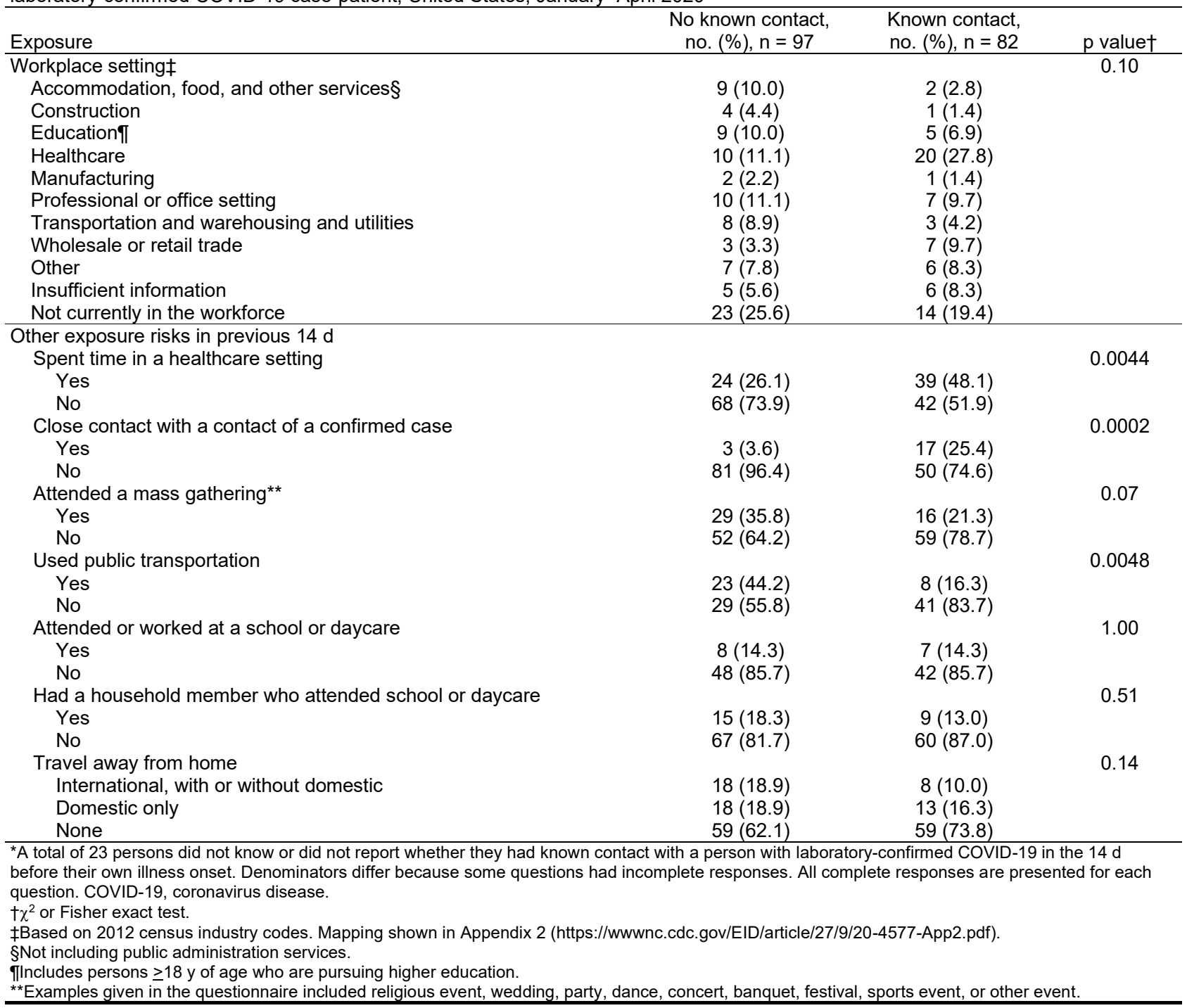

from 2 to 16 persons (median 4 persons) and comprised a variety of household types (e.g., couples, nuclear families, roommates, multigenerational); household size and members' ages, sexes, and relationships were interrelated. Presumed transmission was more frequently observed in larger households (78\% of households with $\geq 5$ members vs. $39 \%$ of households with $<5$ members; $p=0.005$ ) (Figure 2). Within households with more members, a larger number of household contacts reported symptoms (Figure 2).

Among 201 household contacts, 193 had data on symptom status, of which 62 (32\%; 95\% CI 26\%$39 \%)$ were symptomatic. Sensitivity analysis results showed a similar plausible range of attack rates (21\%-39\%; Appendix 2 Results and Table 1$)$. The median serial interval was 3 days (range 1-10 days).
Although our sample did not have large numbers of index case-patients at the age extremes, household contacts were more likely to be symptomatic if the index case-patient was $<5$ ( 5 households) or $\geq 65$ years of age ( 9 households) (Figure 3, panel A); trends were similar, but the point estimates were significant only for index case-patients $\geq 45$ years of age (vs. index case-patients 18-44 years of age) after adjustment for contact age, contact sex, household size, and relationship of the contact to the index casepatient (Table 2). Adult contacts were symptomatic more often than contacts $<18$ years of age (Figure 3 , panel B), but this association was not significant in adjusted analyses (Table 2). The symptom status of household contacts was also associated with their relationship to the index case-patient (Table 2). Among 
the contacts of 9 index case-patients $<18$ years of age, $11 / 16(69 \%)$ parents, $6 / 13(46 \%)$ siblings, and 2/5 $(40 \%)$ other household contacts later became symptomatic. Among contacts of the 60 adult index casepatients, $12 / 44(27 \%)$ children (range $2-49$ years of age), $12 / 45$ (27\%) spouses/partners, $7 / 16$ (44\%) parents, and 11/42 (26\%) other household contacts became symptomatic. When we restricted the analysis to households in which the CIF subject was the index case-patient, overall trends were similar to those reported above, but small sample sizes precluded adjusted analyses (Appendix 2 Table 2).

Illness severity of the index case-patient could not be assessed in multivariable models because of low sample size and correlation with age. However, among 12 household contacts of 10 index casepatients requiring hospitalization (three 18-44, five $45-64$, and two index case-patients $\geq 65$ years of age), only 2 were symptomwatic.

\section{Discussion}

In this convenience sample of 202 early laboratoryconfirmed COVID-19 case-patients, predominantly identified before widespread mitigation measures in the United States, the most commonly reported settings of known exposure were households and healthcare facilities (primarily as a workplace). Within the household, presumed transmission by age of index case-patient followed a U-shaped pattern and was significantly higher among contacts of older $(\geq 65$ years of age) index case-patients than among contacts of index case-patients 18-44 years of age. Independent of index case-patient age, parents of index casepatients were significantly more likely than other household members to report development of symptoms consistent with COVID-19.

Previous research has also found healthcare workplaces and households to be commonly reported settings of COVID-19 acquisition in the United States $(9,10)$. In our analysis, the presumed secondary symptomatic attack rate among household members was 32\%, somewhat high but consistent with estimates from previous studies, ranging from $10 \%$ to $38 \%$ (11-16; J.B. Lopez et al., unpub data, https:/ / www.medrxiv.org/content/10.1101/2020.08.19.2017 7188v1). We found that presumed transmission was highest among contacts of older index case-patients ( $\geq 65$ years of age), even when controlling for contact age category, relationship, and household size; however, our sample size was insufficient to control for underlying conditions or hospitalization status of the index case-patient or for detailed age category of the household contact, which may have confounded
202 confirmed

COVID-19

case-patients

completed CIF

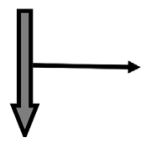

100 lived alone or did

not report symptom

status of any

household contacts

provided symptom

status for $\geq 1$

household contact

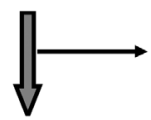

15 case-patients were household

contacts of another included case-patient (data collapsed)

87 unique households

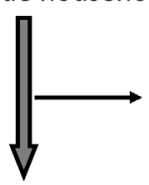

10 case-patients interviewed $\leq 3$ days after symptom onset

- 2 case-patients asymptomatic

- 2 case-patients did not provide onset date

- 4 case-patients with symptom onset same

69 households included day as contact

. 69 index case-patients (48 CIF subjects)

- 62 symptomatic contacts ( $21 \mathrm{CIF}$ subjects)

- 131 asymptomatic contacts

Figure 1. Households included in the analysis population for study of presumed household transmission among persons with COVID-19, United States, January-April 2020. CIF, case investigation form; CIF subject, interviewed COVID-19 casepatient; COVID-19, coronavirus disease.

this relationship because evidence suggests that older adults are more susceptible to COVID-19 (17). Although results were not statistically significant in adjusted analyses, we also found that contacts of index case-patients $<18$ years of age (especially index case-patients $<5$ years of age) were more likely than contacts of index case-patients 18-44 years of age to be symptomatic. Further, symptoms were significantly more likely to develop in parents of index case-patients than in other household members. This relationship was independent of index case-patient age; however, in 8 households of adult case-patients with parental household members, 6 index case-patients were $<30$ years of age. Higher secondary transmission to the household contacts of younger versus adult or older COVID-19 case-patients has also been reported in analyses from the United Kingdom, South Korea, and Canada (16; B.J. Lopez et al., unpub. data, https:/ / www.medrxiv.org/content/10.1101/2020 .08.19.20177188v1; L.A. Paul, unpub. data, https:// www.medrxiv.org/content/10.1101/2021.03.29.2125 4565v1). These findings may be explained by the fact that SARS-CoV-2-infected children may have similar or higher viral loads than adults (18) and that they may have closer interaction with family members, 
Figure 2. Proportion of households with presumed severe acute respiratory syndrome coronavirus 2 transmission, by household size (including index casepatient), United States, January-April 2020. Shading indicates percentage of households with the specified number of symptomatic household contacts (i.e., excluding index casepatient); households with zero symptomatic contacts (in white) are those in which

presumed household transmission did not occur. $n=$ no. households in each stratum.

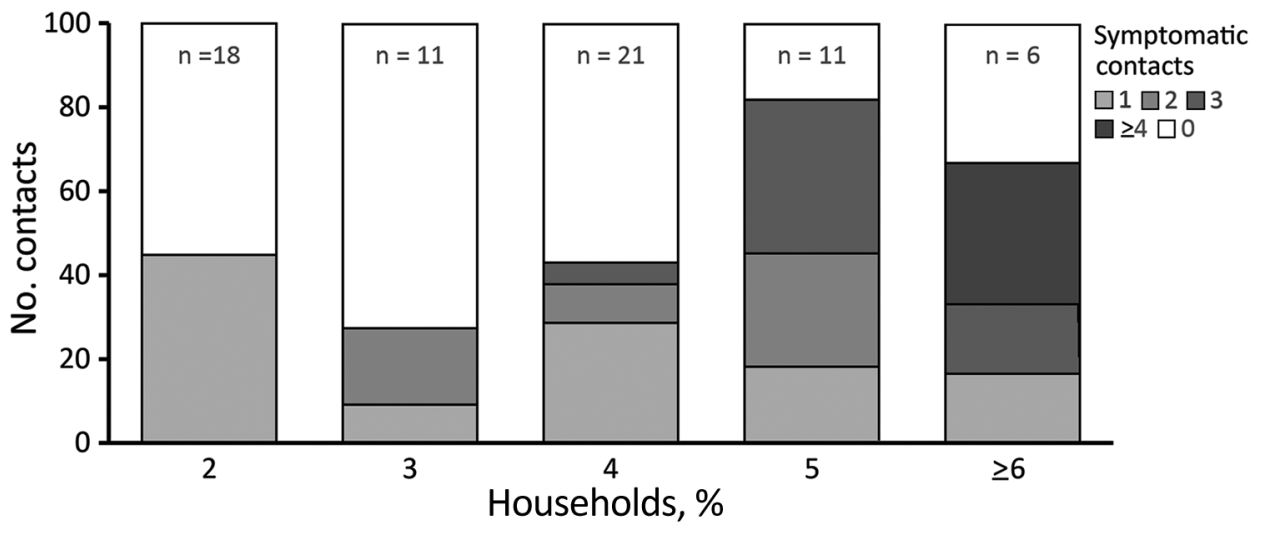

especially parents. Parents, compared with other household members, may also play a greater role in caregiving to index case-patients, even for young adults. Conversely, in multigenerational households, adult children may act as caregivers for elderly parents, possibly exposing them before symptom onset.

A substantial proportion $(60 \%)$ of case-patients in our sample did not report contact with a laboratory-confirmed COVID-19 case-patient in the 14 days before illness onset. Among case-patients without known COVID-19 contact, travel and public activities were more common, although only public transportation use was significantly higher when this group was compared with case-patients with known COVID-19 contact. Public transportation has not been identified as a major source of SARS-CoV-2 transmission (19-21), although transmission on buses, trains, and commercial flights has been reported $(19,22-26)$. However, in our analysis, public transportation use might also have been more common among essential workers, those living in densely populated areas, or those with a history of travel -factors that could also increase opportunity for exposure to SARS-CoV-2 (27). Case-patients reporting no known source of infection, travel, or any other exposure risk factor tended to be older and to have more underlying medical conditions-particularly diabetes mellitus. Persons with concurrent conditions may be not only more susceptible to severe outcomes from COVID-19 $(28,29)$ but also more susceptible to infection, as suggested by other analyses of SARS-CoV-2 $(8,30)$ and Middle East respiratory syndrome coronavirus (31); however, more investigation is warranted.

The first limitation of our study was that the COVID-19 case-patients for whom the CIF was completed are a convenience sample of case-patients reported by 16 states during January -April 2020. Given restricted testing practices in the United States during January-March 2020, these case-patients are not representative of all US COVID-19 case-patients in terms of demographics, clinical characteristics, or exposures. Furthermore, common exposures have varied in time and geography over the course of the epidemic, and it is not possible to exclude the possibility that persons without known COVID-19 exposure had contact with an asymptomatic friend, co-worker, or
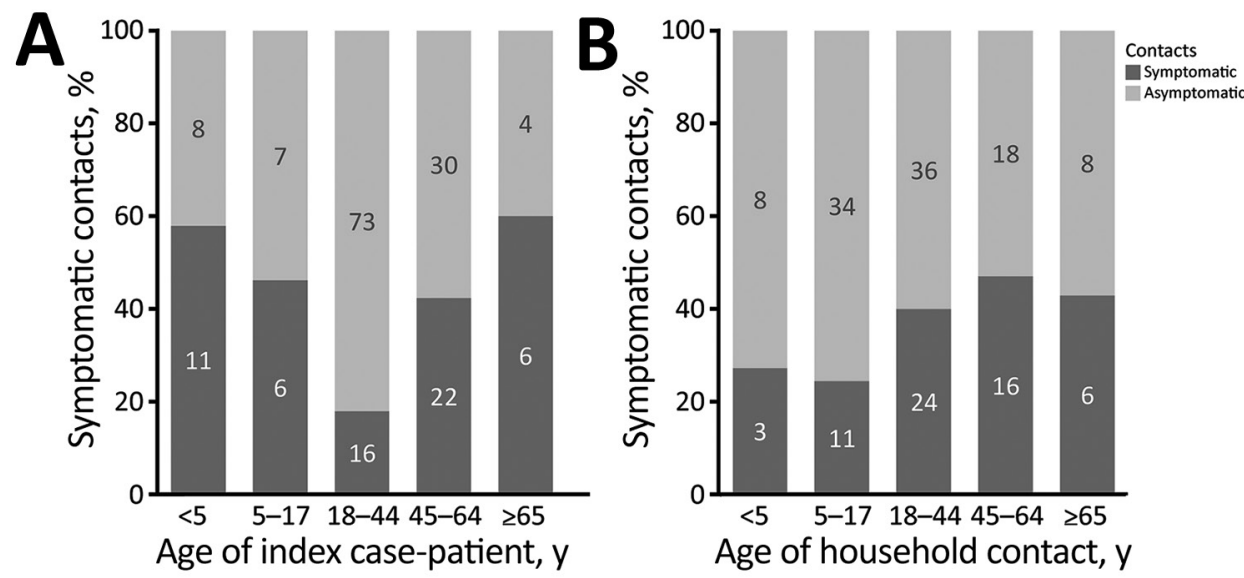

Figure 3. Symptom status of household contacts, by age group of index coronavirus disease case-patient $(n=192)$ and age group of household contact $(n=173)$, United States, January-April 2020. Age group missing for 20 contacts; age of index casepatient missing for 1 contact. 
Table 2. Factors associated with symptom status of 172 household contacts of 64 symptomatic index case-patients in households with presumed COVID-19 transmission, United States, January-April 2020*

\begin{tabular}{|c|c|c|c|c|}
\hline Factor & $\begin{array}{c}\text { Unique } \\
\text { households }\end{array}$ & $\begin{array}{l}\text { No. with symptoms/no. } \\
\text { total contacts }(\%)\end{array}$ & $\operatorname{aOR}(95 \% \mathrm{Cl}) \dagger$ & $\mathrm{p}$ value $\neq$ \\
\hline Contact sex & & & & 0.73 \\
\hline $\mathrm{F}$ & 50 & 28/85 (32.9) & Referent & \\
\hline $\mathrm{M}$ & 46 & 29/87 (33.3) & $0.90(0.49-1.64)$ & \\
\hline Contact age, y & & & & 0.73 \\
\hline$<18$ & 25 & $13 / 50(26.0)$ & Referent & \\
\hline$\geq 18$ & 63 & $44 / 115(38.3)$ & $1.15(0.53-2.47)$ & \\
\hline Household size, persons & & & & 0.006 \\
\hline$<5$ & 48 & 23/92 (25.0) & Referent & \\
\hline$\geq 5$ & 16 & $34 / 80(42.5)$ & $3.56(1.45-8.74)$ & \\
\hline Index case-patient age, y & & & & 0.035 \\
\hline$<5$ & 5 & $11 / 19(57.9)$ & $3.69(0.65-20.95)$ & \\
\hline $5-17$ & 4 & $6 / 13(46.2)$ & $2.09(0.39-11.05)$ & \\
\hline $18-44$ & 26 & $15 / 82(18.3)$ & Referent & \\
\hline $45-64$ & 21 & $20 / 49(40.8)$ & $4.61(1.45-14.66)$ & \\
\hline$\geq 65$ & 8 & $5 / 9(55.6)$ & $15.43(2.28-104.17)$ & \\
\hline Relationship of contact to index case-patient & & & & 0.070 \\
\hline Spouse & 43 & $11 / 44(25.0)$ & Referent & \\
\hline Child & 21 & $11 / 39(28.2)$ & $1.78(0.58-5.45)$ & \\
\hline Parent & 17 & 18/31 (58.1) & $4.55(1.22-17.00)$ & \\
\hline Other§ & 23 & $17 / 58(29.3)$ & $1.47(0.42-5.11)$ & \\
\hline \multicolumn{5}{|c|}{$\begin{array}{l}\text { *A total of } 21 \text { contacts from } 5 \text { households (i.e., } 5 \text { index case-patients) are excluded because of missing data: only relationship data for } 7 \text {, only sex data for } \\
2 \text {, only index case-patient's age for } 1 \text {; only contact's age for } 5 \text {, relationship and contact age for } 6 \text {. Households with presumed transmission } \\
\text { indicates households of laboratory-confirmed COVID- } 19 \text { case-patients where }>1 \text { household member exhibited symptoms; index case-patient indicates } \\
\text { household /member with first reported onset of symptoms (regardless of laboratory confirmation); household contact indicates household member of the } \\
\text { index case-patient. aOR, adjusted odds ratio (adjusted for all variables in the table); COVID-19, coronavirus disease. } \\
\text { tCalculated using robust SEs. } \\
\text { fGeneralized Wald test. } \\
\text { \$lncludes siblings, grandparents, grandchildren, friends, and any household relationship or contact other than spouse, child, or parent. }\end{array}$} \\
\hline
\end{tabular}

family member. Our observed secondary attack rates (symptomatic persons) may also have been affected by the timing of the investigation because public awareness regarding measures to mitigate withinhousehold transmission (e.g., isolation and maskwearing within the home) was probably lower in the early stages of the US epidemic. Information was not collected on the specifics of known COVID-19 exposure, such as mask wearing or social distancing in the home or other exposure settings, because these were not common practices during survey design. The use of a convenience sample may have also affected findings regarding presumed household transmission, such as if selection were biased toward inclusion of more severe cases or larger investigations.

A second limitation is that SARS-CoV-2 infection in most household members was not laboratoryconfirmed, so household members with other causes of illness could have been misclassified as COVID-19 case-patients and those with asymptomatic SARSCoV-2 infections misclassified as non-case-patients. The possibility of misclassification of children may have been higher, given that young children frequently experience respiratory symptoms (32) and are less likely to show symptoms of SARS-CoV-2 infection (33-35). However, overall patterns were similar when analysis was restricted to laboratory-confirmed index case-patients, and the point estimate for odds of presumed symptomatic infection among contacts of index case-patients $<5$ years of age versus contacts of those 18-44 years of age was similar when contacts of unconfirmed index case-patients $<5$ years of age were excluded. In addition, 4 of 5 households with index case-patients $<5$ years of age reported that $\geq 1$ household member attended school or daycare in the 14 days before illness onset in the CIF subject, suggesting a possible outside source of infection. Of note, similar methods are frequently used for studies of influenza (36), and our observed overall symptomatic attack rate and serial interval are consistent with previous knowledge of SARSCoV-2 transmission $(37,38)$. It is also possible that symptoms developed in some household members after the date of interview. To limit this possibility, we excluded households in which the interview took place $<3$ days (median serial interval in our data) after the CIF subject's symptom onset. Similarly, some presumed secondary case-patients may have actually been index case-patients or were co-exposed to the index case-patient; we tested exclusion of contacts with a 1-day lag in symptom onset and found similar trends, although the sample size precluded adjusted models. Previous research showing longer incubation periods for older patients suggests that households with older index patients would be less affected by such misclassification $(39,40)$. 
Last, our sample size was limited by state capacity for participation and data completeness. We did not have sufficient sample size to control for all possible confounders, such as index case-patient signs / symptoms, clinical characteristics, or detailed contact age category, so residual confounding is possible. The lower sample size also limited the precision of our estimates.

Our findings underline the exposure risk associated with work in a healthcare setting and within the household, as previously documented $(9,10)$. However, most case-patients in the analysis did not have known contact with a laboratory-confirmed COVID-19 case-patient, reflecting unrecognized transmission and highlighting the need for widespread testing in addition to community mitigation measures such as masking, hand hygiene, physical distancing, and limiting nonessential travel, as well as vaccination (41-43). When going out in public, persons should take preventive actions and consider the risks associated with public activities by taking into account local orders, their ability to maintain physical distance during the activity, and whether they or their household members are at risk for severe illness from COVID-19 (41). Everyday preventive actions also protect at-risk household members. In this analysis, presumed household transmission was common, especially from the oldest index case-patients and from children to their parents. These findings are especially relevant to the context of in-person schooling because children exposed at schools or daycare centers may introduce COVID-19 into the home. Special care must be taken to mitigate exposure risks outside the home and to protect household members at high risk for severe COVID-19, such as older persons and those with concurrent conditions. Persons with COVID-19 should follow recommendations to reduce the risk for within-household transmission, such as staying in a separate room, wearing a mask around others, practicing hand and cough hygiene, and frequently cleaning high-touch surfaces (44).

\section{Acknowledgments}

We thank the Alaska Department of Health and Social Services' Sections of Epidemiology and Public Health Nursing, Kimberly Yousey-Hindes, Danyel Olson, Hazal Kayalioglu, Nicole Torigian, Hawaii Department of Health COVID Investigation and Surveillance Response Team, Austin Bell, Kalyla Bilski, Emma Contestabile, Claire Henrichsen, Katherine Schleiss, Samantha Siebman, Emily Holodick, Lisa Nguyen, Kristen Ehresmann, Anna Kocharian, Lin Zhao, Sharon Balter, Rebecca Fisher,
Chelsea Foo, Prabhu Gounder, Jeffrey D. Gunzenhauser, Meredith Haddix, M. Claire Jarashow, Talar Kamali, Moon Kim, Jan King, Dawn Terashita, Elizabeth Traub, Roshan Reporter, Patricia Mottu-Monteon, Anthony Aguiar, Anna Kocharian, Lin Zhao, Richard Crawford, CDC Rhode Island Field Team, CDC Santa Clara County Field Team, CDC Utah Field Team, Holly Biggs, Matt Biggerstaff, Fiona Havers, Amber Haynes, Adriana Lopez, Brian Rha, Katherine Roguski, Mayuko Takamiya, and local and tribal public health agencies.

COVID-19 Case Investigation Form Working Group Members: Neha Balachandran, Rebecca M. Dahl, Mary Dott, Lindsey M. Duca, Zunera Gilani, Aaron Grober, Jessica Leung, John Person, Jessica N. Ricaldi, James J. Sejvar, Tom Shimabukuro, Cuc H. Tran, Hilary Whitham, CDC COVID-19 Response Team; Erica Bye, Kathryn Como-Sabetti, Richard Danila, Ruth Lynfield, Minnesota Department of Health; Howard Chiou, COVID-19 Response Team, Epidemic Intelligence Service, Los Angeles County Department of Public Health; Paula Clogher, Connecticut Emerging Infections Program, Yale School of Public Health; Alissa Dratch, Orange County Healthcare Agency; Amanda Feldpausch, Georgia Department of Public Health; Martin Fenstersheib, Lynn Mello, San Benito County Public Health Services; Mary-Margaret Fill, Tennessee Department of Health; Isaac Ghinai, COVID-19 Response Team, Epidemic Intelligence Service, Chicago Department of Health; Michelle Holshue, COVID-19 Response Team, Epidemic Intelligence Service, Washington Department of Health; Sarah Scott, COVID-19 Response Team, Epidemic Intelligence Service, Maricopa County Public Health.

\section{About the Author}

Dr. Burke is an epidemiologist in the Division of Viral Diseases, National Center for Immunization and Respiratory Diseases, Centers for Disease Control and Prevention. Her research interests include infectious diseases and epidemiology.

\section{References}

1. World Health Organization. Novel coronavirus (2019-nCoV): situation report-1 [cited 2020 Jul 29]. https://www.who.int/docs/default-source/coronaviruse/ situation-reports/20200121-sitrep-1-2019-ncov.pdf? sfvrsn=20a99c10_4

2. Holshue ML, DeBolt C, Lindquist S, Lofy KH, Wiesman J, Bruce H, et al.; Washington State 2019-nCoV Case Investigation Team. First case of 2019 novel coronavirus in the United States. N Engl J Med. 2020;382:929-36. https://doi.org/10.1056/NEJMoa2001191

3. Bialek S, Bowen V, Chow N, Curns A, Gierke R, Hall A, et al.; CDC COVID-19 Response Team. Geographic differences in COVID-19 cases, deaths, and incidence- 
United States, February 12-April 7, 2020. MMWR Morb Mortal Wkly Rep. 2020;69:465-71. https:/ / doi.org/10.15585/ mmwr.mm6915e4

4. US Department of Justice. 15 Days to slow the spread [cited 2020 Jul 29]. https:/ / www.whitehouse.gov/ articles/15-days-slow-spread

5. Kates J, Michaud J, Tolbert J. Stay-at-home orders to fight COVID-19 in the United States: the risks of a scattershot approach [cited 2020 Jul 29]. https:/ / www.kff.org/ coronavirus-policy-watch/stay-at-home-orders-to-fightcovid19

6. Chappell B. All 50 U.S. states have now started to reopen, easing COVID-19 shutdown [cited 2020 Jul 29]. https://www.npr.org/sections/coronavirus-live-updates/ 2020/05/20/859723846/all-50-u-s-states-have-now-startedto-reopen-easing-covid-19-shutdown

7. Centers for Disease Control and Prevention. COVID data tracker [cited 2021 Apr 21]. https:/ / covid.cdc.gov/coviddata-tracker/\#datatracker-home

8. Lewis NM, Chu VT, Ye D, Conners EE, Gharpure R, Laws RL, et al. Household transmission of SARS-CoV-2 in the United States. Clin Infect Dis. 2020 Aug 16 [Epub ahead of print].https:/ / doi.org/10.1093/cid/ciaa1166

9. Tenforde MW, Billig Rose E, Lindsell CJ, Shapiro NI, Files DC, Gibbs KW, et al.; CDC COVID-19 Response Team. Characteristics of adult outpatients and inpatients with COVID-19-11 academic medical centers, United States, March-May 2020. MMWR Morb Mortal Wkly Rep. 2020;69:841-6. https://doi.org/10.15585/ mmwr.mm6926e3

10. Marshall K, Vahey GM, McDonald E, Tate JE, Herlihy R, Midgley CM, et al.; Colorado Investigation Team. Exposures before issuance of stay-at-home orders among persons with laboratory-confirmed COVID-19-Colorado, March 2020. MMWR Morb Mortal Wkly Rep. 2020;69:847-9. https:/ / doi.org/10.15585/mmwr.mm6926e4

11. Li W, Zhang B, Lu J, Liu S, Chang Z, Peng C, et al. The characteristics of household transmission of COVID-19. Clin Infect Dis. 2020;71:1943-6. https:/ / doi.org/10.1093/ cid/ciaa450

12. Rosenberg ES, Dufort EM, Blog DS, Hall EW, Hoefer D, Backenson BP, et al.; New York State Coronavirus 2019 Response Team. COVID-19 testing, epidemic features, hospital outcomes, and household prevalence, New York State-March 2020. Clin Infect Dis. 2020;71:1953-9. https://doi.org/10.1093/cid/ciaa549

13. Wang Z, Ma W, Zheng X, Wu G, Zhang R. Household transmission of SARS-CoV-2. J Infect. 2020;81:179-82. https:/ / doi.org/10.1016/j.jinf.2020.03.040

14. Wu J, Huang Y, Tu C, Bi C, Chen Z, Luo L, et al. Household transmission of SARS-CoV-2, Zhuhai, China, 2020. Clin Infect Dis. 2020;71:2099-108. https://doi.org/10.1093/cid/ ciaa557

15. Jing QL, Liu MJ, Zhang ZB, Fang LQ, Yuan J, Zhang AR, et al. Household secondary attack rate of COVID-19 and associated determinants in Guangzhou, China: a retrospective cohort study. Lancet Infect Dis. 2020;20:1141-50. https://doi.org/10.1016/S1473-3099(20)30471-0

16. Park YJ, Choe YJ, Park O, Park SY, Kim YM, Kim J, et al.; COVID-19 National Emergency Response Center, Epidemiology and Case Management Team. Contact tracing during coronavirus disease outbreak, South Korea, 2020. Emerg Infect Dis. 2020;26:2465-8. https:/ / doi.org/10.3201/ eid2610.201315

17. Goldstein E, Lipsitch M, Cevik M. On the effect of age on the transmission of SARS-CoV-2 in households, schools, and the community. J Infect Dis. 2021;223:362-9. https:/ / doi.org/ 10.1093/infdis/jiaa691

18. Heald-Sargent T, Muller WJ, Zheng X, Rippe J, Patel AB, Kociolek LK. Age-related differences in nasopharyngeal severe acute respiratory syndrome coronavirus 2 (SARS-CoV-2) levels in patients with mild to moderate coronavirus disease 2019 (COVID-19). JAMA Pediatr. 2020;174:902-3. https:// doi.org/10.1001/jamapediatrics. 2020.3651

19. Hu M, Lin H, Wang J, Xu C, Tatem AJ, Meng B, et al. The risk of COVID-19 transmission in train passengers: an epidemiological and modelling study. Clin Infect Dis. 2021;72:604-10.

20. Luo L, Liu D, Liao X, Wu X, Jing Q, Zheng J, et al. Contact settings and risk for transmission in 3410 close contacts of patients with COVID-19 in Guangzhou, China: a prospective cohort study. Ann Intern Med. 2020;173:879-87. https:/ / doi.org/10.7326/M20-2671

21. Heald AH, Stedman M, Tian Z, Wu P, Fryer AA. Modelling the impact of the mandatory use of face coverings on public transport and in retail outlets in the UK on COVID-19-related infections, hospital admissions and mortality. Int J Clin Pract. 2021;75:e13768. https://doi.org/10.1111/ijcp.13768

22. Shen Y, Li C, Dong H, Wang Z, Martinez L, Sun Z, et al. Community outbreak investigation of SARS-CoV-2 transmission among bus riders in eastern China. JAMA Intern Med. 2020;180:1665-71. https:/ / doi.org/10.1001/ jamainternmed.2020.5225

23. Luo K, Lei Z, Hai Z, Xiao S, Rui J, Yang H, et al. Transmission of SARS-CoV-2 in public transportation vehicles: a case study in Hunan Province, China. Open Forum Infect Dis. 2020;7:ofaa430.

24. Hoehl S, Karaca O, Kohmer N, Westhaus S, Graf J, Goetsch U, et al. Assessment of SARS-CoV-2 transmission on an international flight and among a tourist group. JAMA Netw Open. 2020;3:e2018044. https:/ / doi.org/10.1001/ jamanetworkopen.2020.18044

25. Khanh NC, Thai PQ, Quach HL, Thi NH, Dinh PC, Duong TN, et al. Transmission of SARS-CoV 2 during long-haul flight. Emerg Infect Dis. 2020;26:2617-24. https:/ / doi.org/10.3201/ eid2611.203299

26. Yang N, Shen Y, Shi C, Ma AHY, Zhang X, Jian X, et al. In-flight transmission cluster of COVID-19: a retrospective case series. Infect Dis (Lond). 2020;52:891-901. https:/ / doi.org/10.1080/23744235.2020.1800814

27. Figueroa JF, Wadhera RK, Mehtsun WT, Riley K, Phelan J, Jha AK. Association of race, ethnicity, and community-level factors with COVID-19 cases and deaths across U.S. counties. Healthc (Amst). 2021;9:100495. https://doi.org/10.1016/ j.hjdsi.2020.100495

28. Mahumud RA, Kamara JK, Renzaho AMN. The epidemiological burden and overall distribution of chronic comorbidities in coronavirus disease-2019 among 202,005 infected patients: evidence from a systematic review and meta-analysis. Infection. 2020;48:813-33. https://doi.org/ 10.1007/s15010-020-01502-8

29. Yang J, Zheng Y, Gou X, Pu K, Chen Z, Guo Q, et al. Prevalence of comorbidities and its effects in patients infected with SARS-CoV-2: a systematic review and metaanalysis. Int J Infect Dis. 2020;94:91-5. https:/ / doi.org/ 10.1016/j.ijid.2020.03.017

30. de Lusignan S, Dorward J, Correa A, Jones N, Akinyemi O, Amirthalingam $\mathrm{G}$, et al. Risk factors for SARS-CoV-2 among patients in the Oxford Royal College of General Practitioners Research and Surveillance Centre primary care network: a cross-sectional study. Lancet Infect Dis. 2020;20:1034-42. https:/ / doi.org/10.1016/ S1473-3099(20)30371-6 
31. Khudhair A, Killerby ME, Al Mulla M, Abou Elkheir K, Ternanni W, Bandar Z, et al. Risk factors for MERS-CoV seropositivity among animal market and slaughterhouse workers, Abu Dhabi, United Arab Emirates, 2014-2017. Emerg Infect Dis. 2019;25:927-35. https:/ / doi.org/10.3201/ eid2505.181728

32. Troeger C, Blacker B, Khalil IA, Rao PC, Cao J, Zimsen SRM, et al.; GBD 2016 Lower Respiratory Infections Collaborators. Estimates of the global, regional, and national morbidity, mortality, and aetiologies of lower respiratory infections in 195 countries, 1990-2016: a systematic analysis for the Global Burden of Disease Study 2016. Lancet Infect Dis. 2018;18:1191210. https://doi.org/10.1016/S1473-3099(18)30310-4

33. Castagnoli R, Votto M, Licari A, Brambilla I, Bruno R, Perlini $S$, et al. Severe acute respiratory syndrome coronavirus 2 (SARS-CoV-2) infection in children and adolescents: a systematic review. JAMA Pediatr. 2020; 174:882-9. https:// doi.org/10.1001/jamapediatrics.2020.1467

34. Ludvigsson JF. Systematic review of COVID-19 in children shows milder cases and a better prognosis than adults. Acta Paediatr. 2020;109:1088-95. https://doi.org/10.1111/apa.15270

35. Zimmermann P, Curtis N. COVID-19 in children, pregnancy and neonates: a review of epidemiologic and clinical features. Pediatr Infect Dis J. 2020;39:469-77. https:/ / doi.org/10.1097/INF.0000000000002700

36. Cauchemez S, Donnelly CA, Reed C, Ghani AC, Fraser C, Kent CK, et al. Household transmission of 2009 pandemic influenza A (H1N1) virus in the United States. N Engl J Med. 2009;361:2619-27. https://doi.org/10.1056/ NEJMoa0905498

37. Park M, Cook AR, Lim JT, Sun Y, Dickens BL. A systematic review of COVID-19 epidemiology based on current evidence. J Clin Med. 2020;9:E967. https:/ / doi.org/ 10.3390/jcm 9040967

38. Madewell ZJ, Yang Y, Longini IM Jr, Halloran ME, Dean NE. Household transmission of SARS-CoV-2: a systematic review and meta-analysis of secondary attack rate. JAMA Netw Open. 2020;3:e2031756. https:// doi.org/10.1001/ jamanetworkopen.2020.31756

39. Quesada JA, Lopez-Pineda A, Gil-Guillen VF, Arriero-Marin JM, Gutierrez F, Carratala-Munuera C. Período de incubación de la COVID-19: revisión sistemática y metaanálisis. Rev Clin Esp. 2021;221:109-17. https://doi.org/10.1016/j.rce.2020.08.005

40. Tan WYT, Wong LY, Leo YS, Toh MPHS. Does incubation period of COVID-19 vary with age? A study of epidemiologically linked cases in Singapore. Epidemiol Infect. 2020;148:e197. https:// doi.org/10.1017/ S0950268820001995

41. Centers for Disease Control and Prevention. Deciding to go out [cited 2020 Sep 1]. https:/ / www.cdc.gov/ coronavirus/2019-ncov/ daily-life-coping/ deciding-to-goout.html

42. Centers for Disease Control and Prevention. How to protect yourself \& others [cited 2020 Sep 1]. https:/ / www.cdc.gov/ coronavirus/2019-ncov/prevent-getting-sick/prevention.html.

43. Centers for Disease Control and Prevention. Vaccines for COVID-19 [cited 2020 Sep 1]. https:/ / www.cdc.gov/ coronavirus/2019-ncov/vaccines/index.html

44. Centers for Disease Control and Prevention. What to do if you are sick [cited 2020 Sep 1]. https://www.cdc.gov/ coronavirus/2019-ncov/if-you-are-sick/steps-when-sick.html.

Address for correspondence: Rachel M. Burke, Centers for Disease Control and Prevention, 1600 Clifton Rd NE, Mailstop H24-5, Atlanta, GA 30329-4027, USA; email: rburke@cdc.gov

\section{EID Podcast Oral HPV Infection in Children, Finland}

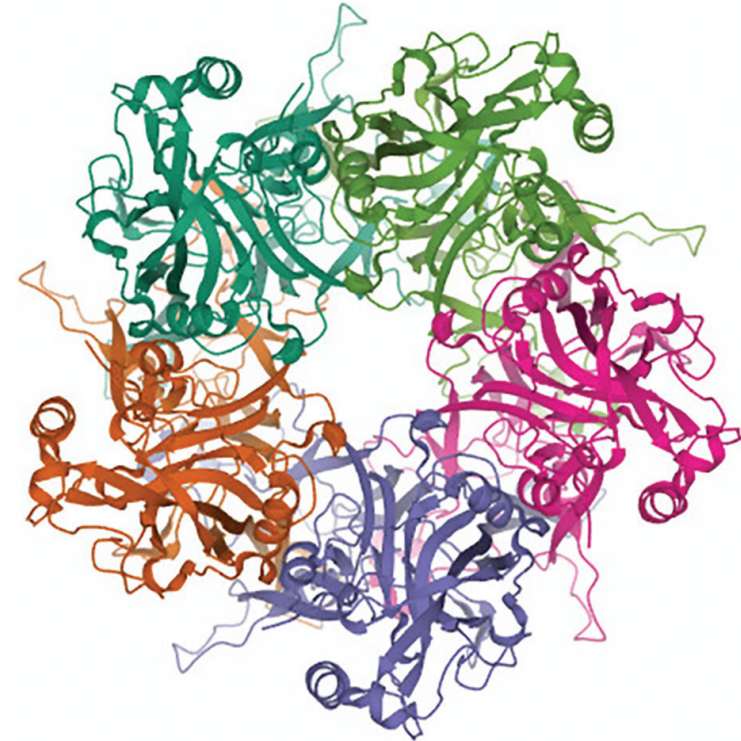

Image credit: Wikimedia Commons, Deposition authors: Bishop, B., Dasgupta, J., Chen, X.S.; http://www.rcsb.org/structure/2r5k

Human papillomavirus (HPV) is usually thought of as a sexually transmitted infection. However, HPV also can spread through other forms of contact. New research indicates that it might even be common for mothers to transmit the virus to their children before, during, and after birth. In this EID podcast, Dr. Stina Syrjänen, a professor and chairman emerita at the University of Turku and chief physician in the Department of Pathology at Turku University Hospital in Finland, describes her findings on nonsexual transmission of HPV among young children and families.

\section{Visit our website to listen: https: / / go.usa.gov/xHKGj}

EMERGING

INFECTIOUS DISEASES ${ }^{\circ}$ 